\title{
Estimation of the Clinical and Economic Impact of an Improvement in Adherence Based on the Use of Once-Daily Single-Inhaler Triple Therapy in Patients with COPD
}

This article was published in the following Dove Press journa:

International Journal of Chronic Obstructive Pulmonary Disease

\author{
Marc Miravitlles (D) ${ }^{1,2}$ \\ Alicia Marín iD ${ }^{2,3}$ \\ Alicia Huerta (iD 4 \\ David Carcedo 5 \\ Alba Villacampa ${ }^{5}$ \\ Jaume Puig-Junoy ${ }^{6}$ \\ 'Pneumology Department, Hospital \\ Universitari Vall d'Hebron, Vall d'Hebron \\ Institut De Recerca (VHIR), Vall \\ d'Hebron Hospital Campus, Barcelona, \\ Spain; ${ }^{2}$ CIBER De Enfermedades \\ Respiratorias (CIBERES), Barcelona, \\ Spain; ${ }^{3}$ Pneumology Department, \\ Hospital Germans Trias I Pujol, Badalona, \\ Spain; ${ }^{4}$ Market Access Department, \\ GlaxoSmithKline SA, Madrid, Spain; \\ ${ }^{5}$ Hygeia Consulting SL, Madrid, Spain; \\ ${ }^{6}$ Barcelona School of Management, \\ Universitat Pompeu Fabra (BSM-UPF), \\ Barcelona, Spain
}

Background: Adherence to treatment is key to achieve desired outcomes. In COPD, adherence is generally suboptimal and is impaired by treatment complexity.

Objective: To estimate the clinical and economic impact of an improvement in treatment adherence due to an increased use of once-daily single-inhaler triple therapy (SITT) in patients with COPD.

Patients and Methods: A 7-state Markov model with monthly cycles was developed. Patients with moderate-to-very severe COPD, for whom triple therapy is indicated, were included. Outcomes and costs were estimated and compared for two scenarios: current distribution of adherent patients treated with multiple inhaler triple therapies (MITT) vs a potential scenario where patients shifted to once-daily SITT. In the potential scenario, adherence improvement due to once-daily SITT attributes was estimated. Costing was based on the Spanish National Health System (NHS) perspective (€2019). A 3-year time horizon was defined considering a 3\% discount rate for both costs and outcomes.

Results: A target population of 185,111 patients with moderate-to-very severe COPD currently treated with MITT was estimated. A $20 \%$ increase in the use of once-daily SITT in the potential scenario raised adherence up to $52 \%$. This resulted in 6835 exacerbations and 532 deaths avoided, with 775 LYs and 594 QALYs gained. Total savings reached $€ 7,082,105$. Exacerbation reduction accounted for $61.8 \%(€ 4,378,201)$ of savings.

Conclusion: Increasing the use of once-daily SITT in patients with moderate-to-very severe COPD treated with triple therapy would be associated with an improvement in adherence, a reduction of exacerbations and deaths, and cost savings for the Spanish NHS.

Keywords: COPD, adherence, healthcare, economic evaluation

\section{Introduction}

Chronic obstructive pulmonary disease (COPD) is a progressive and debilitating respiratory disease, ${ }^{1}$ and one of the most prevalent diseases in the world. ${ }^{2}$ In Spain, the EPI-SCAN study (the Epidemiologic Study of COPD in Spain) estimated a COPD prevalence of $10.2 \%$ among people aged $40-80$ years. $^{3}$ COPD is the fourth leading cause of death worldwide, after ischaemic heart disease, stroke, and lower respiratory infections. ${ }^{4}$

The most common symptoms of COPD are dyspnea, cough and sputum production, which are associated with an increased risk of exacerbations, a worse
Correspondence: Marc Miravitlles Pneumology Department, Hospital Universitari Vall d'Hebron, P. Vall d'Hebron II9-129, Barcelona 08035, Spain

Tel/Fax +34932746083

Email marcm@separ.es 
prognosis of the disease and a clinically meaningful decrease in the patients' quality of life. ${ }^{5}$ An acute exacerbation of COPD is an episode of worsening of a patient's respiratory symptoms and constitutes a life-threatening event. $^{6}$

Due to the incurable nature of COPD, the goal of treatment is to control the symptoms, reduce exacerbations and improve patients' quality of life. ${ }^{1}$ The Global Initiative for Obstructive Lung Disease (GOLD) management strategy recommends triple therapy with inhaled corticosteroids (ICS), long-acting beta-agonists (LABA), and long-acting muscarinic antagonists (LAMA) for patients who develop further exacerbations after receiving dual treatment with LABA and LAMA combinations. ${ }^{7,8}$ The Spanish COPD Guidelines (GesEPOC) also recommend triple therapy with LAMA/LABA/ICS for high-risk patients who do not present good control of exacerbations with two drugs (either two long-acting bronchodilators or a long-acting bronchodilator + ICS). ${ }^{9-11}$

Poor adherence to treatment is estimated to contribute to nearly 200,000 premature deaths in Europe per year. ${ }^{12}$ Patients with chronic conditions such as hypertension, diabetes or COPD are particularly vulnerable to poor health outcomes if they do not adhere to their medications. ${ }^{12}$ Adherence in patients with COPD is particularly poor, with non-adherence rates ranging from $50 \%$ to $80 \%{ }^{13-15}$

Poor adherence is due to many reasons, such as socioeconomic factors, therapy-related factors and patientrelated factors. ${ }^{16}$ Specifically, in COPD, there are factors directly related to inhaled therapy such as the complexity of treatment, problems with the use of the device and patients' preferences. ${ }^{17,18}$ This poor adherence in patients with COPD is associated with worse clinical outcomes and health status, and increased urgent care use compared with patients with better adherence. ${ }^{19-22}$

Reducing treatment complexity could lead to better adherence rates and improved clinical outcomes for patients with COPD, which could lead to reductions in associated healthcare costs. ${ }^{17,18}$ In this regard, recently launched single-inhaler triple therapies (SITT) reduce treatment complexity for patients treated with triple therapy.

Within the Treatment Adherence Plan (responsible use of medication), Farmaindustria (the national trade association of the Spanish-based pharmaceutical industry) developed a model to estimate the clinical and economic impact associated with an adherence increase in patients with
COPD. ${ }^{23}$ According to this analysis, more than $€ 8.5$ million in direct health expenditures would be saved, and 1089 deaths and more than 20,000 exacerbations would be avoided with a $1 \%$ increase of the average level of adherence. ${ }^{23}$

Based on the rationale used by Farmaindustria, the aim of this study was to estimate the clinical and economic impact of an improvement in treatment adherence due to an increased use of once-daily SITT in patients with moderate-to-very severe COPD already treated with triple therapy. ${ }^{23}$ The study also assessed if this increased use of once-daily SITT could be a cost-effective intervention from the Spanish National Health System (NHS) perspective.

It is expected that treatment simplification by increasing use of once-daily SITT instead of multiple-inhaler triple therapies (MITT) leads to better adherence rates, improved clinical outcomes and a reduction in associated healthcare costs.

\section{Methods}

The analysis performed by Farmaindustria was based on a published Markov model developed by Rutten van Mölken et $\mathrm{al}^{24}$ so the same rationale was considered here. A model designed to evaluate the impact of an improvement in treatment adherence in patients with COPD has been developed.

In this analysis, the model compared two different scenarios in which the proportion of adherent and nonadherent patients was modified due to different uses of SITT vs MITT. The model estimates the clinical outcomes and associated healthcare costs. The rationale of the analysis, main assumptions, parameters and results obtained in the analysis were validated by a panel of two clinical experts and one expert in health economics through face-to -face and telephone meetings.

\section{Model Structure}

A 7-state Markov model comprising three health states representing COPD severity (moderate, severe and very severe, based on pulmonary function) was replicated. From each health, state patients could transition to three exacerbation health states, and a death state (Figure 1).

The model considered 1-month cycles, except for the first cycle, that lasted 8 days to obtain enough granularity to properly estimate costs and benefits.

A time horizon of 3 years was considered, in line with previously published analyses in COPD. ${ }^{25}$ A $3 \%$ discount 

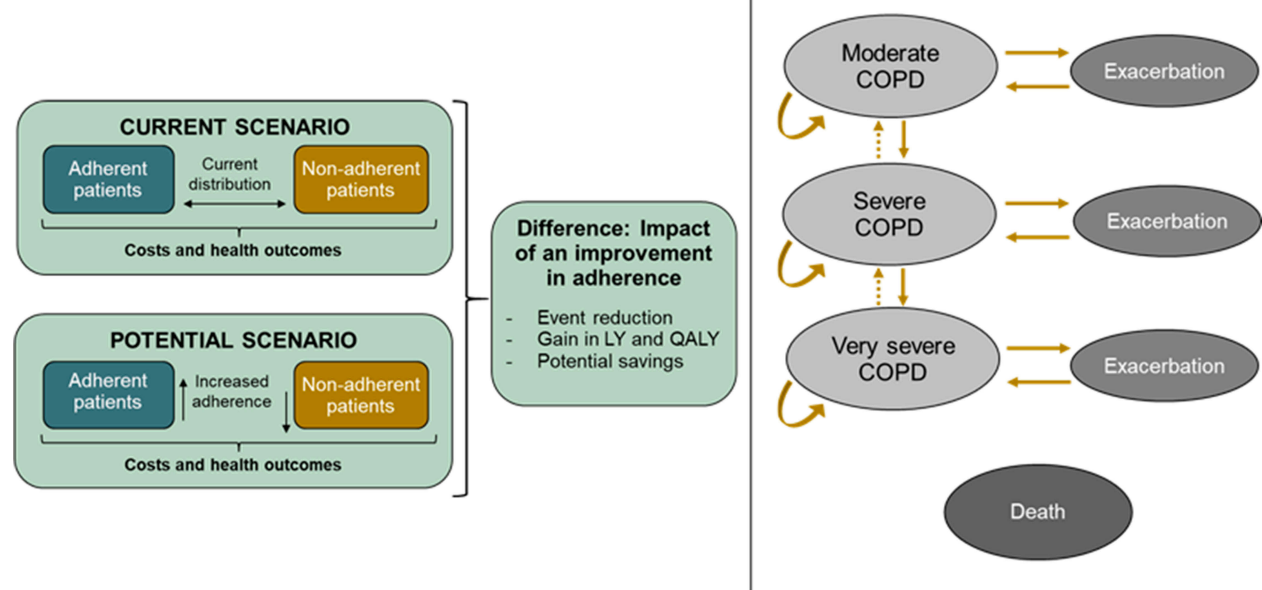

Figure I Diagram of Markov model and rationale of the analysis. Patients continue in the health state. Patients transiting to other health states. Abbreviations: LY, life years; QALY, quality-adjusted life years; COPD, chronic obstructive pulmonary disease.

rate was applied for costs and effects occurring after the first year of the analysis, based on local guidelines. ${ }^{26,27}$

During the first year of the analysis, both forward (transitions to worse disease states) and backward (transitions to better disease states) transitions between model health states were possible. Backward transitions during the second and third years were not allowed, reflecting the progressive nature of $\mathrm{COPD}{ }^{24}$

The analysis is based on the comparison of two different scenarios:

- Current scenario, with the current proportion of adherent and non-adherent patients, assuming that all patients use MITT.

- Potential scenario, with an increased proportion of adherent patients based on a greater use of SITT instead of MITT.

\section{Target Population}

The target population included in the analysis was composed of adult patients with moderate-to-very severe COPD (according to GOLD classification) ${ }^{7,8}$ currently treated with triple therapy. In the current scenario, it was assumed that all patients were treated with MITT, while in the potential scenario patients would receive either MITT or SITT.

Quantification of the target population was performed using a top-down approach. Starting from the general population in Spain aged $40-80$ years,${ }^{28}$ a COPD prevalence of $10.20 \%$ was applied (Figure 2). ${ }^{3,29}$ To estimate the number of patients on treatment, the $45.3 \%$ of patients with COPD receiving active treatment reported by Soriano et $\mathrm{al}^{29}$ was considered as a proportion (Figure 2). Finally, to estimate how many patients would be treated with triple therapy, a real-world database consisting of electronic medical records from 1.9 million patients of 7 autonomous communities in Spain was consulted (Figure 2). ${ }^{30}$

In the current scenario, the estimated target population was divided between adherent and non-adherent patients considering a distribution based on published evidence. In Spain, a study performed by the Observatory of Adherence to Treatment (OAT) estimated that $49.5 \%$ of patients with COPD are non-adherent. ${ }^{31}$ Another study conducted by

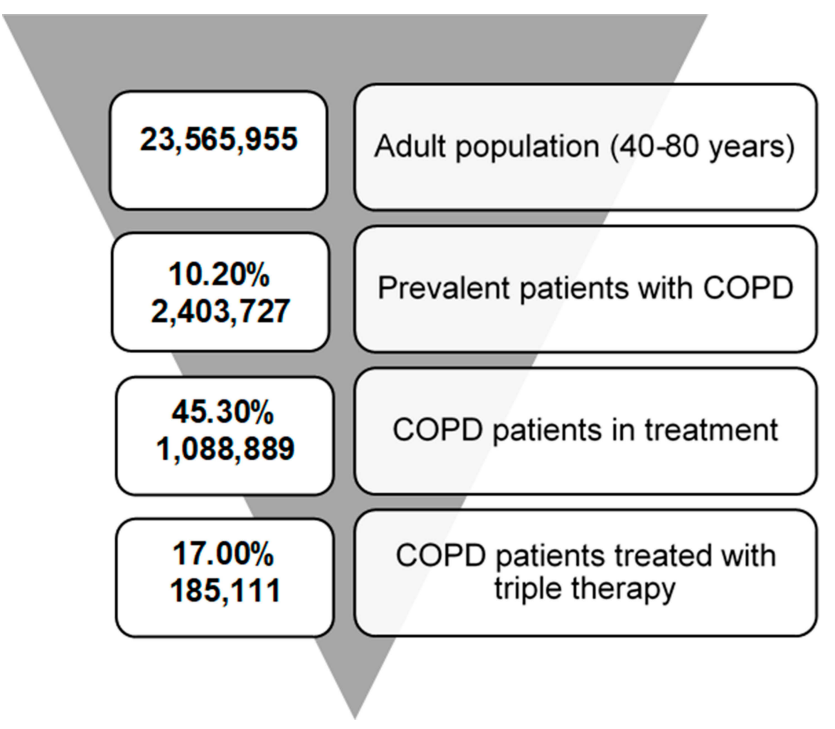

Figure 2 Estimation of target population. Source: ${ }^{3,28-30}$

Abbreviation: COPD, chronic obstructive pulmonary disease. 
Plaza et $\mathrm{al}^{32}$ reported that $49 \%$ of patients with COPD were classified as adherent patients. Based on these studies, the panel of experts agreed to consider the current percentage of adherent patients as $49 \%$, based on the study carried out by Plaza et al. ${ }^{32}$

Once patients entered the model, independent of their adherence classification, they had to be distributed based on COPD severity. Patients' baseline distribution among the three health states representing COPD severity was based on an economic evaluation developed by Rutten van Mölken et al. ${ }^{24}$ Thus, during the first cycle, $55.2 \%$ of patients had moderate disease, $34.9 \%$ had severe disease and $9.9 \%$ had very severe disease.

\section{Transition Probabilities}

Transition probabilities were obtained from a previous economic evaluation performed by Rutten van Mölken et $\mathrm{al}^{24}$ and incorporated in the model for the adherent patients, since this data was obtained from six clinical trials comparing tiotropium versus salmeterol, ipratropium or placebo. Exacerbation probabilities considered in the model and reported by Rutten van Mölken et $\mathrm{al}^{24}$ for the tiotropium arm were based on the pooled patient-level data from all six clinical trials (additional data are given in Online Resource 1).

To estimate the transition probabilities for the nonadherent patients, correction factors were applied to the transition probabilities defined for the adherent patients. These factors were obtained from the TORCH study. This analysis reported that adequate adherence was associated with a $44 \%$ lower rate of developing severe exacerbations (rate ratio: $0.56,95 \%$ confidence interval [CI]: 0.48-0.65), and a $60 \%$ decreased risk of death (hazard ratio: $0.4,95 \%$ CI: $0.35-0.46)^{20}$ (additional data are given in Online Resource 2).

\section{Adherence Improvement}

To estimate the extent to which once-daily SITT would increase the proportion of adherent patients in the potential scenario, a literature review was carried out.

Different SITT attributes that could affect adherence were defined. Attributes related to treatment complexity (ie, use of multiple inhalers versus a single inhaler, and increased number of daily doses), inhalers' characteristics, inhalation technique, or patient preferences have been reported to influence treatment adherence or even clinical outcomes. ${ }^{18}$

After consulting the expert panel, the attributes that would have greater influence on a potential adherence improvement, that were therefore considered in the present analysis, were the number of inhalers used and the daily number of treatment administrations. Equally important attributes, such as the type of device used or patients' preferences, were not included in the base-case analysis since their effects were more difficult to estimate as there was no evidence quantifying a direct relationship with an adherence improvement.

To quantify a combined effect considering the number of inhalers used and the number of daily doses, independence was assumed between these two variables.

Within the current scenario, there were patients receiving triple therapy once daily (od) and patients receiving a twice daily (bid) regimen. Based on market data, ${ }^{33}$ only $15.8 \%$ of patients receive triple therapy od, corresponding to those patients using fluticasone furoate/vilanterol (Relvar) plus tiotropium (Spiriva). Regarding the number of inhalers used, all patients were using two inhalers (MITT) in the current scenario.

The studies selected to establish the relationship between the selected attributes and adherence were developed by $\mathrm{Yu}$ et $\mathrm{al}^{34}$ for the single versus multiple inhalers, and by Toy et $\mathrm{al}^{35}$ for od versus bid. The first study reported that adherence in the multiple-inhaler cohort was significantly lower than that observed for a singleinhaler cohort by $8.6 \%{ }^{34}$ The second study reported that the differential adherence between patients with od dose or bid dose was $6.3 \%$ (43.3\% in od and $37.0 \%$ in bid).

To quantify the adherence improvement due to an increased use of once-daily SITT in the potential scenario, the following formulae were used:

\section{ADH1inh * POP1inh + ADH2inh * POP2inh $=$ Overall_Adh}

Where ADH1inh and POP1inh are the proportion of adherent patients among those using 1 inhaler and the percentage of patients using 1 inhaler, respectively. ADH2inh and POP2inh are the proportion of adherent patients among those using 2 inhalers and the percentage of patients using 2 inhalers, respectively. Overall_Adh is the current percentage of adherent patients globally.

\section{ADHod $*$ POPod + ADHbid $*$ POPbid $=$ Overall $\_$Adh}

Where ADHod and POPod are the proportion of adherent patients among those receiving a od dose and the percentage of patients receiving a od dose, respectively. ADHbid and POPbid are the proportion of adherent patients among those receiving a bid dose and the percentage of patients 
receiving a bid dose, respectively. Overall_Adh is the current percentage of adherent patients globally.

Using the data reported by Yu et $\mathrm{al}^{34}$ and Toy et $\mathrm{al}^{35}$ in the described equations, the adherent proportions of patients using one or two inhalers, and among patients with od or bid administration, were populated and solved.

Thus, it is possible to re-weight the equations with a greater use of once-daily SITT (variables POP1inh and POPod) and to estimate the new overall adherence in the potential scenario of the analysis considering a $20 \%$ increase in use of once-daily SITT for the base case, raising the proportion of adherent patients up to $52 \%$.

\section{Costs}

The base-case analysis was carried out from the perspective of the Spanish National Health System (NHS), therefore direct healthcare costs were included: drug costs, disease management costs and exacerbation costs, all expressed in euros $(€) 2019$.

Pharmacological costs associated with triple therapy were expressed in terms of retail price plus value added tax (PTP+VAT), applying the corresponding deductions according to Royal Decree-Law 8/2010. ${ }^{36,37}$

For the current scenario, daily cost associated with MITT was calculated considering the market distribution of all possible combinations (Table 1).

For the potential scenario, cost per day was reweighted based on an incremental use of once-daily SITT, specifically with fluticasone furoate/umeclidinium/ vilanterol (Trelegy ELLIPTA) with a daily cost of $€ 2.58 .^{36}$ This was selected as it was the only approved SITT administered od at the time of the analysis.

Monthly cost was calculated considering the estimated daily cost for the current and potential scenarios, assuming a differential adherence adjustment for the adherent and non-adherent patient cohorts. It is widely accepted that adherent patients are defined as taking at least $80 \%$ of their medication. ${ }^{38}$ After consulting the expert panel, a 0.9 adjustment in the adherent cohort $(90 \%$ of total cost) and 0.65 adjustment in the non-adherent cohort ( $65 \%$ of the total cost) was considered. This adjustment applied starting from the second cycle of the model, assuming that during the 8 days of the first cycle the adherence would be $100 \%$.

Exacerbation costs were obtained from an economic evaluation developed by Miravitlles et $\mathrm{al},{ }^{39}$ and they were updated to $€ 2019$ using the Spanish General Consumer
Table I Pharmacological Costs of the Triple Therapy (MITT)

\begin{tabular}{|c|c|c|c|c|}
\hline \multicolumn{2}{|l|}{ Combination } & \multirow{2}{*}{$\begin{array}{l}\text { Market } \\
\text { Share } \\
\% \text { group: } \\
81 \%\end{array}$} & \multicolumn{2}{|c|}{ Daily Cost, $€$} \\
\hline $\begin{array}{l}\text { LABA/ICS + } \\
\text { LAMA }\end{array}$ & $\begin{array}{l}\text { Trade } \\
\text { name }\end{array}$ & & Individual & Weighted \\
\hline $\begin{array}{l}\text { Salmeterol/ } \\
\text { fluticasone }\end{array}$ & Seretide & $39.9 \%$ & 1.376 & \multirow[t]{5}{*}{2.80} \\
\hline $\begin{array}{l}\text { Formoterol/ } \\
\text { budesonide }\end{array}$ & Symbicort & $20.5 \%$ & 1.542 & \\
\hline $\begin{array}{l}\text { Beclometasone/ } \\
\text { formoterol }\end{array}$ & Fostair & $23.8 \%$ & 1.589 & \\
\hline $\begin{array}{l}\text { Vilanterol/ } \\
\text { fluticasone }\end{array}$ & Relvar & $15.8 \%$ & 1.589 & \\
\hline Tiotropium & Spiriva & $100.0 \%$ & 1.308 & \\
\hline $\begin{array}{l}\text { LAMA/LABA + } \\
\text { ICS }\end{array}$ & & $\begin{array}{l}\text { \% group: } \\
19 \%\end{array}$ & Individual & Weighted \\
\hline $\begin{array}{l}\text { Indacaterol/ } \\
\text { glycopyrronium }\end{array}$ & Ultibro & $44.7 \%$ & 2.652 & \multirow[t]{5}{*}{3.02} \\
\hline $\begin{array}{l}\text { Olodaterol/ } \\
\text { tiotropium }\end{array}$ & Spiolto & $32.9 \%$ & 2.513 & \\
\hline $\begin{array}{l}\text { Umeclidinium/ } \\
\text { vilanterol }\end{array}$ & Anoro & $5.6 \%$ & 2.166 & \\
\hline $\begin{array}{l}\text { Aclidinium/ } \\
\text { formoterol }\end{array}$ & Duaklir & $16.8 \%$ & 2.166 & \\
\hline Budesonide & Pulmicort & $100.0 \%$ & 0.526 & \\
\hline \multicolumn{4}{|c|}{ Weighted daily cost for MITT } & 2.84 \\
\hline
\end{tabular}

Notes: Source: Market share ${ }^{33}$ and Daily cost. ${ }^{36}$

Abbreviations: ICS, inhaled corticosteroid; LABA, long-acting beta-agonist; LAMA, long-acting muscarinic antagonist; MITT, multiple-inhaler triple therapy.

Price Index (Table 2) ${ }^{40}$ In the current model, exacerbations were moderate and severe. Severe exacerbations were defined in the economic evaluation developed by Rutten van Mölken et $\mathrm{al}^{24}$ as requiring hospitalization, and the rest of the exacerbations were classified as moderate (not requiring hospitalization).

Once an exacerbation occurred (according to the transition probabilities described above), the probability that the exacerbation would be severe was obtained from Rutten van Mölken et $\mathrm{al}^{24}$ (probabilities are given in Online Resource 3).

Management costs by disease severity shown in Table 2, were estimated considering the annual healthcare resource consumption reported by Rutten van Mölken et al. ${ }^{24}$ Spanish unit costs were applied to this resource 
Table 2 Costs of Disease Management and Exacerbations

\begin{tabular}{|l|l|l|l|}
\hline & \multicolumn{2}{|l|}{ Management Costs, $€$} & \multirow{2}{*}{ Source } \\
\cline { 2 - 3 } & $\begin{array}{l}\text { 8-Days } \\
\text { Cycle }\end{array}$ & $\begin{array}{l}\text { I-Month } \\
\text { Cycle }\end{array}$ & \\
\hline Moderate COPD & 6.99 & 26.61 & $\begin{array}{l}\text { See Online } \\
\text { resource 4 }\end{array}$ \\
\hline Severe COPD & 9.81 & 37.32 & $\begin{array}{l}\text { See Online } \\
\text { resource 4 }\end{array}$ \\
\hline $\begin{array}{l}\text { Very severe } \\
\text { COPD }\end{array}$ & 13.92 & 52.98 & $\begin{array}{l}\text { See Online } \\
\text { resource 4 }\end{array}$ \\
\hline $\begin{array}{l}\text { Moderate } \\
\text { exacerbation }\end{array}$ & 73.62 & Exacerbation costs, $€$ & Miravitlles et al ${ }^{39}$ \\
\hline $\begin{array}{l}\text { Severe } \\
\text { exacerbation }\end{array}$ & 4519.24 & Miravitlles et al ${ }^{39}$ \\
\hline
\end{tabular}

Note: Source: Healthcare resources; ${ }^{24}$ and current unit cost ${ }^{39,41}$.

Abbreviation: COPD, chronic obstructive pulmonary disease.

consumption. $^{41}$ Annual management cost was translated into monthly costs in order to fit with the model cycle length (detailed estimation of management costs in additional data given in Online Resource 4).

\section{Utilities}

Utility values reported by Miravitlles et $\mathrm{al}^{42}$ by COPD severity in Spain were associated with "moderate COPD", "severe COPD" and "very severe COPD" heath states of the model (Table 3). During cycles in which patients experienced an exacerbation, a percentage of disutility was applied to the utility value defined and applied for the main health state. These disutilities were obtained from Rutten van Mölken et al ${ }^{24}$ (Table 3).

\section{Sensitivity Analysis}

To evaluate the uncertainty associated with some parameters included in the model and to determine the
Table 4 Deterministic Sensitivity Analysis Values

\begin{tabular}{|c|c|c|}
\hline Parameter & Base Case & $\begin{array}{l}\text { Alternative } \\
\text { Value }\end{array}$ \\
\hline \multirow[t]{2}{*}{ Utilities } & \multirow[t]{2}{*}{ Mean values ${ }^{42}$} & Median values ${ }^{42}$ \\
\hline & & $\begin{array}{l}\text { Mean, range } \\
\text { defined by } \\
\pm 20 \%\end{array}$ \\
\hline Exacerbation cost & $\begin{array}{l}\text { Moderate } \\
\text { exacerbation: } \\
€ 73.62^{39} \\
\text { Severe exacerbation: } \\
€ 4519.24^{39}\end{array}$ & $\begin{array}{l}\text { Range defined } \\
\text { by } \pm 20 \%\end{array}$ \\
\hline $\begin{array}{l}\text { Monthly management } \\
\text { cost }\end{array}$ & $\begin{array}{l}\text { Moderate COPD: } \\
€ 26.6 \text { I (calculated) } \\
\text { Severe COPD: } \\
€ 37.32 \text { (calculated) } \\
\text { Very severe COPD: } \\
€ 52.98 \text { (calculated) }\end{array}$ & $\begin{array}{l}\text { Range defined } \\
\text { by } \pm 20 \%\end{array}$ \\
\hline $\begin{array}{l}\text { Probability that a given } \\
\text { exacerbation is severe }\end{array}$ & $\begin{array}{l}\text { Moderate COPD: } \\
0.097^{24} \\
\text { Severe COPD: } \\
0.136^{24} \\
\text { Very severe } \\
\text { COPD:0.192 }\end{array}$ & $\begin{array}{l}\text { Range defined } \\
\text { by } \mathrm{SE}^{24}\end{array}$ \\
\hline $\begin{array}{l}\text { Lower rate of } \\
\text { exacerbation in adherent } \\
\text { cohort }\end{array}$ & RR: $0.56^{20}$ & $\begin{array}{l}\text { Range defined } \\
\text { by } 95 \% \mathrm{Cl}^{20}\end{array}$ \\
\hline $\begin{array}{l}\text { Decreased risk of death } \\
\text { in adherent cohort }\end{array}$ & HR: $0.40^{20}$ & $\begin{array}{l}\text { Range defined } \\
\text { by } 95 \% \mathrm{Cl}^{20}\end{array}$ \\
\hline
\end{tabular}

Note: Source: ${ }^{20,24,39,42}$.

Abbreviations: COPD, chronic obstructive pulmonary disease; RR, rate ratio; HR, hazard ratio; $\mathrm{SE}$, standard error; $\mathrm{Cl}$, confidence interval.

robustness of the results obtained, both deterministic and probabilistic sensitivity analyses were performed.

Through the deterministic analysis, methodological alternatives to the base case analysis were tested, and the main parameters of the model were modified individually within a given range (Table 4).

Table 3 Utility Values

\begin{tabular}{|l|l|l|l|l|}
\hline \multirow{2}{*}{} & \multicolumn{2}{|l|}{ Utility Value } & \multicolumn{2}{l|}{ Utility Decrement (Disutility) in Case of } \\
\cline { 2 - 5 } & Mean (SE) & Median (SE) & Moderate Exacerbation & Severe Exacerbation \\
\hline Moderate COPD & $0.82(0.01893)$ & $0.87(0.01893)$ & & $50 \%$ \\
Severe COPD & $0.72(0.02408)$ & $0.80(0.02159)$ & $15 \%$ & 50 \\
Very severe COPD & $0.57(0.04308)$ & $0.66(0.05170)$ & & \\
\hline
\end{tabular}

Note: Source: ${ }^{42}$.

Abbreviations: COPD, chronic obstructive pulmonary disease; SE, standard error. 
In the probabilistic analysis, 1000 simulations were performed using second-order Monte Carlo methodology, simultaneously modifying the costs (gamma distribution), increased risk of death and exacerbation development in the non-adherent patients' cohort (log-normal distribution) and utilities (beta distribution).

\section{Results}

A target population of 185,111 patients was estimated (Figure 2). Considering an increase of $20 \%$ in the use of once-daily SITT in the potential scenario as a base case, after a time horizon of 3 years, 532 fewer deaths and 6835 fewer exacerbations were predicted in the potential scenario compared with the current scenario. Thus, a gain of 775 LYs and 594 QALYs was obtained in the potential scenario (Table 5).

Savings were almost $€ 7.1$ million for the Spanish NHS when comparing the potential scenario with the current scenario (Table 5). These savings were a consequence of a reduction in exacerbations ( $€ 4.4$ million), accounting for $61.8 \%$ of the overall savings. Exacerbation costs accounted for $35.8 \%$ of total direct costs, considering both scenarios. Drug costs, which accounted for $42.3 \%$ of total direct costs, were also lower in the potential scenario due to the lower price of fluticasone furoate/umeclidinium/vilanterol compared to MITT, accounting for $€ 3.1$ million in savings ( $43.9 \%$ of the overall savings). Disease management associated costs, which accounted for $21.9 \%$ of the total direct costs, were $€ 0.4$ million higher in the potential scenario.

As the use of once-daily SITT increased, a higher proportion of patients were adherent, and therefore clinical results improved and savings increased (Table 6). For example, increasing the use of once-daily SITT up to $40 \%$ (54.98\% of adherent patients), increased the number of avoided deaths from 532 in the base case to 1064, and total savings reached $€ 14.3$ million.

As it was hypothesized that adherent patients might have higher pharmaceutical costs than non-adherent patients, increased use of once-daily SITT could have resulted in additional overall costs instead of savings. A cost-effectiveness analysis was therefore performed to assess the effect of incorporating such an intervention and incremental costeffectiveness ratios were obtained. In the base case, use of once-daily SITT resulted in a dominant strategy, increasing QALY gain and decreasing costs compared to MITT (Tables 5 and 6). In summary, increasing the use of once-daily SITT improved QALY gains and led to savings (Table 6).

Table 5 Detailed Results for Health Outcomes and Costs, Base Case

\begin{tabular}{|c|c|c|c|c|c|c|c|}
\hline & \multicolumn{3}{|c|}{ Current Scenario } & \multicolumn{3}{|c|}{ Potential Scenario } & \multirow{2}{*}{$\begin{array}{l}\text { Impact } \\
\text { (Potential } \\
\text { vs Current) }\end{array}$} \\
\hline & Adherent & Non-Adherent & Total & Adherent & Non-Adherent & Total & \\
\hline \multicolumn{8}{|l|}{ Health outcomes } \\
\hline \multicolumn{8}{|l|}{ Events } \\
\hline COPD deaths & 6,94 & 16,312 & 23,252 & 7362 & 15,359 & 22,72 & -532 \\
\hline Exacerbations & 187,099 & 311,455 & 498,554 & 198,472 & 293,247 & 491,719 & -6835 \\
\hline \multicolumn{8}{|l|}{ Life years } \\
\hline Total LY & 238,362 & 234,593 & 472,954 & $252,85 I$ & 220,878 & 473,729 & 775 \\
\hline Per patient LY & 2.627 & 2.486 & 51.127 & 2.627 & 2.486 & 51.127 & 0.0042 \\
\hline Total QALY & 174,882 & 171,676 & 346,558 & 185,513 & 161,64 & 347,152 & 594 \\
\hline Per patient QALY & 1.927 & 1.819 & 37.464 & 1.927 & 1.819 & 37.464 & 0.0032 \\
\hline \multicolumn{8}{|l|}{ Costs } \\
\hline Pharmacological cost $(€)$ & $226,312,873$ & $161,465,592$ & $387,778,465$ & $235,523,14 \mid$ & $149,146,614$ & $384,669,754$ & $-3,|08,7| 1$ \\
\hline Management disease cost (€) & $101,095,093$ & $98,194,489$ & $199,289,582$ & $107,240,526$ & $92,453,863$ & $199,694,389$ & 404,806 \\
\hline Exacerbation cost $(€)$ & $124,524,722$ & $204,370,869$ & $328,895,591$ & $132,094,410$ & $192,422,980$ & $324,517,390$ & $-4,378,201$ \\
\hline Total direct cost $(€)$ & $451,932,688$ & $464,030,950$ & $915,963,638$ & $474,858,077$ & $434,023,456$ & $908,881,533$ & $-7,082,105$ \\
\hline
\end{tabular}

Abbreviations: COPD, chronic obstructive pulmonary disease; LY, life years; QALY, quality-adjusted life years. 
Table 6 Incremental Health and Cost for an Increased Use of SITT (Single-Inhaler Triple Therapies)

\begin{tabular}{|c|c|c|c|c|c|c|c|}
\hline \multirow{2}{*}{$\begin{array}{l}\text { SITT Use } \\
\text { Increment }\end{array}$} & \multirow[t]{2}{*}{$\%$ of Adherent Patients } & \multicolumn{6}{|c|}{ Results: Potential Scenario vs Current Scenario } \\
\hline & & Exacerb. & Deaths & LYs & QALYs & $\begin{array}{l}\text { Exacerbation } \\
\text { Costs }\end{array}$ & Total Direct Costs \\
\hline Increment $20 \%$ SITT & $52.00 \%$ & -6835 & -532 & 775 & 594 & $-€ 4,378,201$ & $-€ 7,082,105$ \\
\hline Increment $40 \%$ SITT & $54.98 \%$ & $-13,669$ & -1064 & 1550 & 1189 & $-€ 8,756,217$ & $-€ \mid 4,327,774$ \\
\hline Increment $60 \%$ SITT & $57.94 \%$ & $-20,504$ & -1595 & 2325 & 1783 & $-€ \mid 3,134,232$ & $-€ 21,736,991$ \\
\hline Increment $80 \%$ SITT & $60.94 \%$ & $-27,338$ & -2127 & 3100 & 2377 & $-€|7,5| 2,248$ & $-€ 29,309,757$ \\
\hline Increment $100 \%$ SITT & $63.12 \%$ & $-32,323$ & -2515 & 3665 & 2811 & $-€ 20,705,555$ & $-€ 37,028,592$ \\
\hline
\end{tabular}

Abbreviations: SITT, single-inhaler triple therapies; LY, life years; QALY, quality-adjusted life years.

\section{Sensitivity Analysis}

To facilitate interpretation of the deterministic sensitivity analysis results described in Table 4, a tornado diagram (Figure 3) was used to represent the variation in the parameters that were individually modified (one-way sensitivity analysis).

The results of the probabilistic sensitivity analysis were represented in a cost-effectiveness plane (Figure 4). All simulations were located in the fourth quadrant, indicating that increased use of SITT is a dominant strategy.

\section{Discussion}

In this analysis, the clinical and economic impact of an improvement in treatment adherence (due to increased use of once-daily SITT) in patients with moderate-to-very severe COPD has been estimated over a 3-year time period in Spain using an economic model. The results from this analysis show that an increase of $20 \%$ in the use of once-daily SITT could avoid 532 deaths and 6835 exacerbations, with a gain of 775 LYs and 594 QALYs; thus leading to $€ 7.1$ million potential savings for the Spanish NHS.
Medication adherence is a key factor to achieve desired treatment outcomes. Nevertheless, several epidemiological studies suggest that adherence remains suboptimal in most patients, ${ }^{12,43}$ especially in patients suffering from chronic conditions such as COPD.

Several studies have established a correlation between adherence to inhaled therapies for COPD and clinical efficacy, with improved symptom control and lung function with increased adherence. Reductions in healthcare utilization are also consistently observed with good adherence, and both medical (inpatient) and total costs are likely to decrease in adherent patients. ${ }^{19}$ Non-adherence is associated with higher healthcare utilization and costs, and reductions in health-related quality of life, and remains problematic on an individual, societal and economic level. ${ }^{17}$

Adherence is an outcome that is influenced by a number of interconnected factors related to the patient, the provider, and the healthcare system. ${ }^{12}$ In COPD, the reasons for suboptimal adherence to inhaled therapies are multifactorial and can be classified as drug factors

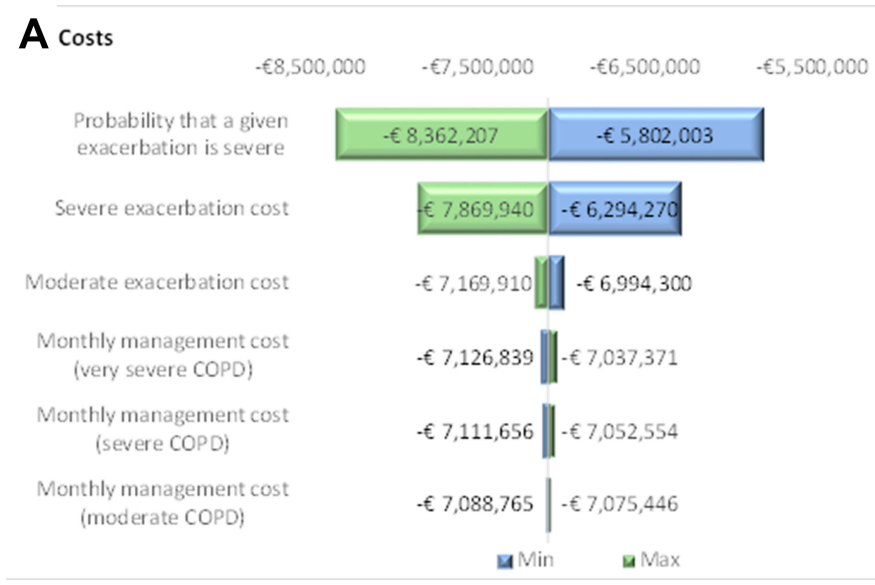

B aAlYs

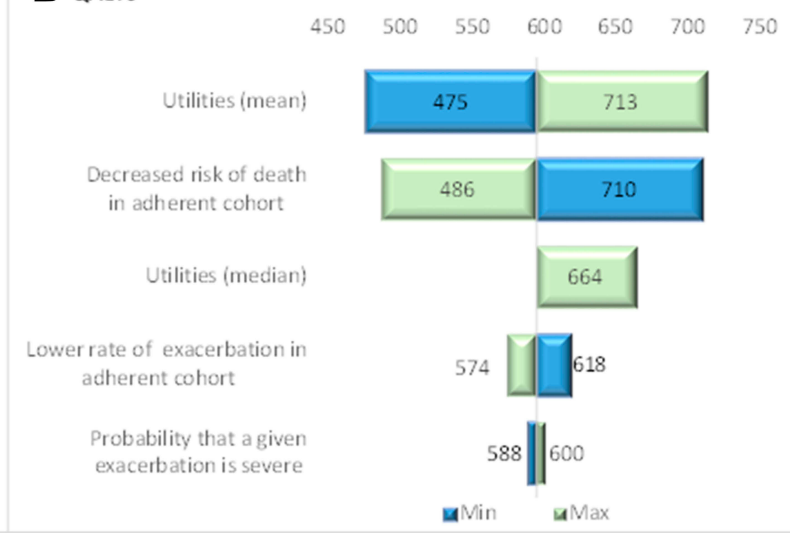

Figure 3 Tornado diagram. (A) Results expressed in total direct costs; (B) Results expressed in total QALYs.

Abbreviations: COPD, chronic obstructive pulmonary disease; QALY, quality-adjusted life year. 


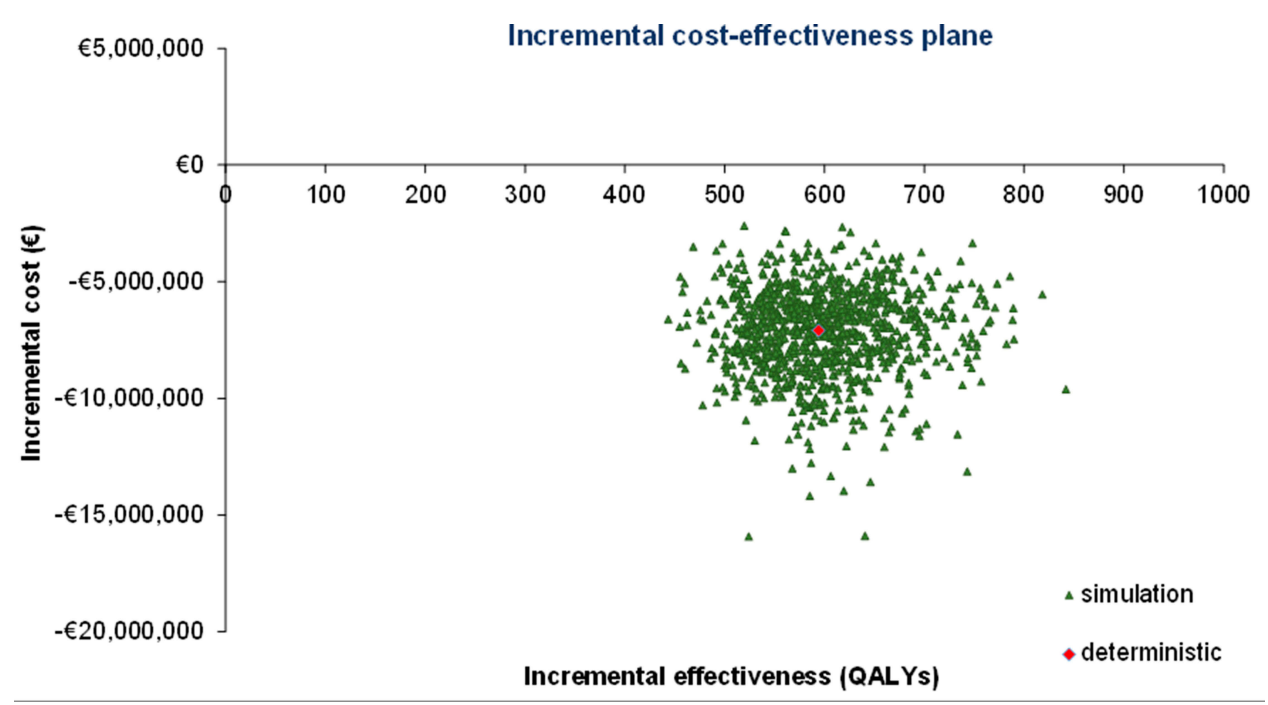

Figure 4 Cost-effectiveness plot. Simulations from the probabilistic sensitivity analysis, and the deterministic point. The green triangle represents the results from the probabilistic sensitivity analysis. The red rhombus represents the base-case result.

Abbreviation: QALY, quality-adjusted life year.

(difficulties with inhaler devices, complex regimens, side effects, medication costs, etc.) and non-drug factors (misunderstanding or lack of instruction, dissatisfaction with healthcare professionals, unexpressed/undiscussed fears or concerns, poor supervision, training or follow-up, underestimation of disease severity, etc.). ${ }^{17}$ Assessing patients' satisfaction with their inhaler devices is a useful patientreported outcome, helping to correlate adherence with treatment, patient satisfaction and clinical outcomes. ${ }^{44}$

Treatment simplification has been demonstrated to increase adherence rates. Increased treatment complexity (ie, use of multiple inhalers for delivery of maintenance treatments and increased number of daily doses) is associated with poor persistence and adherence in patients with COPD. ${ }^{18,34,35}$

Our study is, to the best of our knowledge, the first one to estimate the increment in adherence associated with the introduction of SITT and the economic and clinical consequences of such intervention. This estimation of improvement in adherence, is based on two attributes of SITT: those with greater relevance according to experts. Using SITT, with its od administration regimen and the use of only one inhaler, would likely result in an increase in the proportion of adherent patients. This increase could also lead to savings for the Spanish NHS and better health outcomes for patients. However, as adherence is affected by multiple different factors, our estimation of the increment in adherence due to the introduction of SITT and the consequent economic and clinical results, could be different if more attributes of SITT that may affect treatment adherence were taken into account. Nevertheless, uncertainty associated with this estimation was assessed in the sensitivity analysis.

In Spain, the relationship between treatment adherence in COPD and costs and clinical outcomes was estimated in two economic analyses. Darbà et $\mathrm{al}^{45}$ estimated the economic impact of the introduction of a budesonide/formoterol fixed-dose combination for the treatment of patients with COPD, focusing on an increase in medication adherence due to enhancement of the inhalation technique. Overall, the total budget savings for Spain was expected to be $€ 6.01$ million over the following 4 years. ${ }^{45}$ The previously described Farmaindustria model, on which the current analysis was based, estimated savings of $€ 8.5$ million with an increase of $1 \%$ in the proportion of adherent patients. ${ }^{23}$

Our analysis is not exempt of limitations. Some are inherent to pharmacoeconomic models, which are characterized by a degree of structural rigidity that can make it difficult to offer an appropriate representation of the clinical reality. For example, transition probabilities for both the adherent and non-adherent cohorts were estimated based on the probabilities reported in Rutten van Mölken et $\mathrm{al}^{24}$ in the context of a clinical trial and adjusted according to decreased risks reported in the TORCH study. ${ }^{20}$ This approach was considered the most appropriate, given the lack of real-world evidence or studies specially designed to establish differences in outcomes between 
adherent and non-adherent patients with COPD. In the same way, some assumptions had to be made regarding the estimation of the improvement of adherence associated with a greater use of SITT. The efficacy, safety and impact of SITT on healthcare resource utilization in patients with COPD have been assessed, ${ }^{46,47}$ but the improvement in adherence with SITT vs MITT has not been reported. Therefore, for the estimation of adherence improvement in our analysis (based on two attributes of SITT), independence between the two selected variables had to be assumed. A study specifically designed for this purpose would be necessary to quantify the combined effect of these two variables, but no published data were identified at the time of the analysis.

The analysis also presents limitations regarding the costs. Pharmacological cost of triple therapy is one of the key drivers for the economic outcomes. Conservatively, it was assumed that patients with good adherence to treatment are more expensive for the Spanish NHS than nonadherent patients. No study was found that allowed us to quantify this difference to adjust the pharmacological cost in both the adherent and non-adherent cohorts, so expert opinion was used to establish the adjustment factors.

Regarding the costs of exacerbations, these were incorporated into the model in the cycles in which an exacerbation occurs, in addition to routine management costs. If the exacerbation was severe (less frequent than moderate), there could have been some double counting as severe exacerbations require hospitalization (mean length: 8 days), and therefore drug costs would be included in the defined unit cost.

Given the perspective of the analysis, indirect costs were not included in the base case. Some studies have calculated the indirect costs associated with COPD in Spain, ${ }^{48,49}$ but those studies do not report the indirect costs specifically associated with exacerbations. Despite the advanced age of patients with COPD, if a societal perspective was adopted, the savings could have been slightly higher.

To overcome or minimize these limitations and the associated uncertainty, we performed several sensitivity analyses that confirmed the robustness of the results obtained. Furthermore, all of the assumptions made, the parameters considered and the results obtained were subject to validation by the group of experts. Also, the description of the methods was sufficiently transparent to allow adaptation of the model and transferability of the results from one setting to another.

\section{Conclusion}

Our analysis showed that increasing use of once-daily SITT in patients with moderate-to-very severe COPD, in whom triple therapy is indicated, was associated with an improvement in patients' healthcare and savings for the Spanish NHS. These results were due to SITT attributes regarding od administration and the use of one inhaler, being a dominant strategy in all sensitivity analyses performed. Further studies specifically designed to assess the improvement in adherence associated with the use of SITT in real life are needed.

\section{Funding}

This study was funded by GlaxoSmithKline plc. (study number: HO-18-19453). Trademarks are owned by or licensed to their respective owners (the GlaxoSmithKline group of companies or AstraZeneca UK Ltd; Boehringer Ingelheim Ltd; Chiesi Ltd; or Novartis Pharmaceuticals UK Ltd). The abstract of this paper was presented at the European Respiratory Society International Congress 2019 name "Clinical and economic impact of an improvement in adherence based on specific attributes of single-inhaler triple therapies in COPD patients" as a poster presentation with interim findings. The poster's abstract was published in the European Respiratory Journal 2019 Vol 54 Issue suppl 63: PA4194; DOI: 10.1183/13993003.congress2019.PA4194. Available at: https://erj.ersjournals.com/con tent/54/suppl 63/PA4194.

\section{Disclosure}

MM has received speaker or consulting fees from AstraZeneca, Bial, Boehringer Ingelheim, Chiesi, Cipla, CSL Behring, Laboratorios Esteve, Ferrer, Gebro Pharma, GlaxoSmithKline, Grifols, Menarini, Mereo Biopharma, Novartis, pH Pharma, Rovi, Sandoz, Sanofi, Spin Therapeutics, TEVA, Verona Pharma and Zambon, and research grants from GlaxoSmithKline and Grifols. AM has received speaker or consulting fees from Boehringer Ingelheim, Chiesi, Pfizer, Laboratorios Esteve, GlaxoSmithKline, Menarini, Novartis, and Zambon. $\mathrm{AH}$ was an employee of GlaxoSmithKline at the time of the study was conducted. DC and AV are employees of Hygeia Consulting SL. Hygeia received funding from GlaxoSmithKline to conduct the analysis. JPJ received fees for the participation in the study. The authors report no other conflicts of interest in this work. 


\section{References}

1. Lim KE, Kim SR, Kim HK, Kim SR. Symptom clusters and quality of life in subjects with COPD. Respir Care. 2017;62:1203-1211. doi: $10.4187 /$ respcare. 05374

2. Díaz-Guzman E, Mannino DM. Epidemiology and prevalence of chronic obstructive pulmonary disease. Clin Chest Med. 2014;35:7-16. doi:10.1016/j.ccm.2013.10.002

3. Miravitlles M, Soriano JB, García-Río F, et al. Prevalence of COPD in Spain: impact of undiagnosed COPD on quality of life and daily life activities. Thorax. 2009;64:863-868. doi:10.1136/thx.2009.115725

4. World health organization (WHO), 2019. Global Health Observatory (GHO) data. Mortality and global health estimates. Available from: https://www.who.int/gho/mortality_burden_disease/en/. Accessed June, 2019

5. Miravitlles M, Ribera A. Understanding the impact of symptoms on the burden of COPD. Respir Res. 2017a;18:67. doi:10.1186/s12931017-0548-3

6. Casas-Mendez F, Abadías MJ, Yuguero O, et al. Treatment strategies after acute exacerbations of chronic obstructive pulmonary disease: impact on mortality. PLoS One. 2018;13:e0208847. doi:10.1371/journal.pone. 0208847

7. Vogelmeier CF, Criner GJ, Martínez FJ, et al. Global strategy for the diagnosis, management, and prevention of chronic obstructive lung disease 2017 report: GOLD executive summary. Arch Bronconeumol. 2017;53:128-149. doi:10.1016/j.arbres.2017.02.001

8. Singh D, Agusti A, Anzueto A, et al. Global strategy for the diagnosis, management, and prevention of chronic obstructive lung disease: the GOLD science committee report 2019. Eur Respir J. 2019;53(5):pii: 1900164. doi:10.1183/13993003.00164-2019

9. Miravitlles M, Soler-Cataluña JJ, Calle M, et al. Spanish guidelines for management of chronic obstructive pulmonary disease (GesEPOC) 2017. Pharmacological treatment of stable phase. Arch Bronconeumol. 2017b;53:324-335. doi:10.1016/j.arbres.2017.03.018

10. Calle Rubio M, Rodríguez Hermosa JL, Soler-Cataluña JJ, et al. Medical care according to risk level and adaptation to Spanish COPD guidelines (GesEPOC): the epoconsul study. Arch Bronconeumol. 2018;54:270-279. doi:10.1016/j.arbres.2017.11.015

11. Izquierdo JL, Miravitlles M, Esquinas C, et al. Characteristics of COPD patients managed in respiratory medicine departments in Spain, according to GOLD groups and GesEPOC clinical phenotypes. Arch Bronconeumol. 2018;54:559-567. doi:10.1016/j. arbres.2018.03.021

12. Khan R, Socha-Dietrich $\mathrm{K}$ Investing in medication adherence improves health outcomes and health system efficiency: adherence to medicines for diabetes, hypertension, and hyperlipidaemia. OECD Health Working Papers. No. 105. OECD Publishing:Paris. Available from: https://www.oecd-ilibrary.org/docserver/8178962c-en.pdf? expires $=1571733795 \& \mathrm{id}=\mathrm{id} \& \mathrm{acc}$ ame $=$ guest $\&$ checksum $=$ E01A3272F1055DE80E6FE325648B4CE3. Accessed June, 2019

13. Humenberger M, Horner A, Labek A, et al. Adherence to inhaled therapy and its impact on chronic obstructive pulmonary disease (COPD). BMC Pulm Med. 2018;18:163. doi:10.1186/s12890-0180724-3

14. Restrepo RD, Alvarez MT, Wittnebel LD, et al. Medication adherence issues in patients treated for COPD. Int $J$ Chron Obstruct Pulmon Dis. 2008:3:371-384. doi:10.2147/COPD.S3036

15. George M. Adherence in asthma and COPD: new strategies for an old problem. Respir Care. 2018;63:818-831. doi:10.4187/respcare.05905

16. Kardas P, Lewek P, Matyjaszczyk M. Determinants of patient adherence: a review of systematic reviews. Front Pharmacol. 2013;4:91. doi:10.3389/fphar.2013.00091

17. Mäkelä MJ, Backer V, Hedegaard M, Larsson K. Adherence to inhaled therapies, health outcomes and costs in patients with asthma and COPD. Respir Med. 2013;107:1481-1490. doi:10.1016/j. rmed.2013.04.005
18. King D, Zhang S, Rosen V, Ismaila AS Single versus multiple inhalers in patients with chronic obstructive pulmonary disease (COPD): a systematic literature review. Poster PMD17. Presented at: ISPOR European Congress; November 4-8; 2017; Glasgow.

19. Van Boven JF, Chavannes NH, van der Molen T, et al. Clinical and economic impact of non-adherence in COPD: a systematic review. Respir Med. 2014;108:103-113. doi:10.1016/j.rmed.2013.08.044

20. Vestbo J, Anderson JA, Calverley PM, et al. Adherence to inhaled therapy, mortality and hospital admission in COPD. Thorax. 2009;64:939-943. doi:10.1136/thx.2009.113662

21. Chrystyn H, Small M, Milligan G, et al. Impact of patients' satisfaction with their inhalers on treatment compliance and health status in COPD. Respir Med. 2014;108:358-365. doi:10.1016/j.rmed.2013.09.021

22. Ismaila A, Corriveau D, Vaillancourt J, et al. Impact of adherence to treatment with tiotropium and fluticasone propionate/salmeterol in chronic obstructive pulmonary diseases patients. Curr Med Res Opin. 2014;30:1427-1436. doi:10.1185/03007995.2014.908828

23. Farmaindustria. Plan de adherencia al tratamiento. Uso responsable del medicamento; 2016. Available from: http://www.farmaindustria. es/adherencia/. Accessed April, 2019

24. Rutten-van Mölken MP, Oostenbrink JB, Miravitlles M, Monz BU. Modelling the 5-year cost effectiveness of tiotropium, salmeterol and ipratropium for the treatment of chronic obstructive pulmonary disease in Spain. Eur J Health Econ. 2007;8:123-135. doi:10.1007/ s10198-007-0039-4

25. Rutten-van Mölken MP, Goossens LM. Cost effectiveness of pharmacological maintenance treatment for chronic obstructive pulmonary disease: a review of the evidence and methodological issues. Pharmacoeconomics. 2012;30:271-302. doi:10.2165/11589270000000000-00000

26. Lopez-Bastida J, Oliva J, Antoñanzas F, et al. Propuesta de guía para la evaluación económica aplicada a las tecnologías sanitarias. Gac Sanit. 2010;24:154-170. doi:10.1016/j.gaceta.2009.07.011

27. Puig-Junoy J, Oliva-Moreno J, Trapero-Bertrán M, et al. Guía y recomendaciones para la realización y presentación de evaluaciones económicas y análisis de impacto presupuestario de medicamentos en el ámbito del CatSalut. Barcelona: Servei Català de la Salut (CatSalut); 2014.

28. Instituto Nacional de Estadística (INE). Estadistica del padrón continuo. Datos provisionales a 1 de enero de 2018. Available from: www.ine.es. Accessed April, 2019

29. Soriano JB, Miravitlles M, Borderías L, et al. Geographical variations in the prevalence of COPD in Spain: relationship to smoking, death rates and other determining factors. Arch Bronconeumol. 2010;46:522-530. doi:10.1016/j.arbres.2010.06.008

30. Real Patient Data - Big Pac. Pacientes en tratamiento farmacológico para la EPOC. Movimiento Total Anual (MAT) a Q2 2018. Real Life Data SLU. Available from: www.rlifedata.com. Accessed April, 2019

31. Observatorio de adherencia al tratamiento (OAT). Estudio Nacional de la adherencia al tratamiento en patologías crónicas. Available from: https://www.oatobservatorio.com/. Accessed April, 2019

32. Plaza V, López-Viña A, Entrenas LM, et al. Differences in adherence and non-adherence behaviour patterns to inhaler devices between COPD and asthma patients. COPD. 2016;13:547-554. doi:10.3109/ 15412555.2015.1118449

33. IQVIA. Pharmaceutical market database. Triple therapies sales, 2019 (data on file). Available from: https://www.iqvia.com/. Accessed July 8, 2020.

34. Yu AP, Guérin A, Ponce de Leon D, et al. Therapy persistence and adherence in patients with chronic obstructive pulmonary disease: multiple versus single long-acting maintenance inhalers. J Med Econ. 2011;14:486-496.

35. Toy EL, Beaulieu NU, McHale JM, et al. Treatment of COPD: relationships between daily dosing frequency, adherence, resource use, and costs. Respir Med. 2011;105:435-441. doi:10.1016/j. rmed.2010.09.006 
36. BotPlus 2.0. Drug database of the general council of pharmaceutical colleges. Portalfarma. Available from: https://botplusweb.portal farma.com/. Accessed April, 2019

37. Ministry of Health. Royal decree-law 8/2010. Extraordinary measures to reduce the public deficit. Boletín Oficial del Estado; 2010. Available from: http://www.boe.es/boe/dias/2010/05/24/pdfs/BOEA-2010-8228.pdf. Accessed April, 2019

38. Baumgartner PC, Haynes RB, Hersberger KE, Arnet I. A systematic review of medication adherence thresholds dependent of clinical outcomes. Front Pharmacol. 2018;9:1290. doi:10.3389/ fphar.2018.01290

39. Miravitlles M, Gáldiz JB, Huerta A, et al. Cost-effectiveness of combination therapy umeclidinium/vilanterol versus tiotropium in symptomatic COPD Spanish patients. Int J Chron Obstruct Pulmon Dis. 2016;11:123-132. doi:10.2147/COPD.S94006

40. Instituto Nacional de Estadística (INE). Índice de Precios de Consumo. Available from: www.ine.es. Accessed April, 2019

41. Gisbert R, Brosa M Healthcare costs database: eSalud. Barcelona: Oblikue Consulting, S.L. Available from: http://www.oblikue.com/ bddcostes/. Accessed March, 2019

42. Miravitlles M, Huerta A, Fernández-Villar JA, et al. Generic utilities in chronic obstructive pulmonary disease patients stratified according to different staging systems. Health Qual Life Outcomes. 2014;12:120. doi:10.1186/s12955-014-0120-5

43. Van Boven JF, Ryan D, Eakin MN, et al. Enhancing respiratory medication adherence: the role of health care professionals and cost-effectiveness considerations. J Allergy Clin Immunol Pract. 2016;4:835-846. doi:10.1016/j.jaip.2016.03.007
44. Karampitsakos T, Hillas G2, Zervas E, et al. Prospective evAluatIon foR inhalation devices in Greek patients with COPD and asthma: the PAIR study. Pulm Pharmacol Ther. 2020;60:101882. doi:10.1016/j. pupt.2019.101882

45. Darbà J, Ramírez G, García-Rivero JL, et al. Estimating the economic consequences of an increased medication adherence due to a potential improvement in the inhaler technique with Spiromax ${ }^{\circledR}$ compared with Turbuhaler ${ }^{\circledR}$ in patients with moderate to severe chronic obstructive pulmonary disease in Spain. Clinicoecon Outcomes Res. 2017;9:127-137. doi:10.2147/CEOR.S125301

46. Ismaila AS, Birk R, Shah D, et al. Once-daily triple therapy in patients with advanced COPD: healthcare resource utilization data and associated costs from the FULFIL trial. Adv Ther. 2017;34:2163-2172. doi:10.1007/s12325-017-0604-x

47. Lai CC, Chen $\mathrm{CH}$, Lin $\mathrm{CYH}$, et al. The effects of single inhaler triple therapy vs single inhaler dual therapy or separate triple therapy for the management of chronic obstructive pulmonary disease: a systematic review and meta-analysis of randomized controlled trials. Int J Chron Obstruct Pulmon Dis. 2019;14:1539-1548. doi:10.2147/COPD.S200846

48. Miravitlles M, Sicras A, Crespo C, et al. Costs of chronic obstructive pulmonary disease in relation to compliance with guidelines: a study in the primary care setting. Ther Adv Respir Dis. 2013;7:139-150. doi: $10.1177 / 1753465813484080$

49. Merino M, Villoro R, Hidalgo-Vega Á, Carmona C. Social economic costs of COPD in Extremadura (Spain): an observational study. Int J Chron Obstruct Pulmon Dis. 2018;13:2501-2514. doi:10.2147/COPD.S167357

\section{Publish your work in this journal}

The International Journal of COPD is an international, peer-reviewed journal of therapeutics and pharmacology focusing on concise rapid reporting of clinical studies and reviews in COPD. Special focus is given to the pathophysiological processes underlying the disease, intervention programs, patient focused education, and self management protocols. This journal is indexed on PubMed Central, MedLine and CAS. The manuscript management system is completely online and includes a very quick and fair peer-review system, which is all easy to use. Visit http://www.dovepress.com/testimonials.php to read real quotes from published authors. 